\title{
Development of chocolate dairy dessert with addition of prebiotics and replacement of sucrose with different high-intensity sweeteners
}

\author{
E. C. Morais, ${ }^{\star 1}$ A. R. Morais, $†$ A. G. Cruz, $\ddagger$ and H. M. A. Bolini* \\ *Department of Food and Nutrition, Faculty of Food Engineering, University of Campinas, 13083-862, Campinas, SP, Brazil \\ †Department of Exact Sciences, Federal University of Lavras, 37200-000, Lavras, MG, Brazil \\ †Federal Institute of Education, Science and Technology of Rio de Janeiro (IFRJ), Food Department, 20270-021, Rio de Janeiro, RJ, Brazil
}

\begin{abstract}
The aims of this study were (1) to optimize the formulation of a prebiotic chocolate dairy dessert and assess the extent to which sensory properties were affected by adding different concentrations of prebiotics (inulin and fructooligosaccharides) combined with different levels of xanthan and guar gums, and (2) to analyze the ideal and relative sweetness of prebiotic chocolate milk dessert sweetened with different artificial and natural sweeteners. Acceptability was evaluated by 100 consumers using a 9-cm hedonic scale, and the level of sample creaminess was evaluated using a 9-point just-about-right (JAR) scale. Data were subjected to a multivariate regression analysis and fitted to a model provided by response surface methodology. The optimal concentrations were $7.5 \%$ (wt/wt) prebiotic and $0.20 \%$ (wt/wt) gum (guar and xanthan, in a 2:1 ratio). The ideal sweetness analysis revealed that the ideal concentration of sucrose was $8.13 \%$. The relative sweetness analysis showed that Neotame (NutraSweet Corp., Chicago, IL) had the highest sweetening power compared with the prebiotic chocolate dairy dessert containing $8 \%$ sucrose, followed by sucralose, aspartame, and stevia. The study of sweetness in this product is important because consumers desire healthier functional products with no added sugar.
\end{abstract}

Key words: just-about-right (JAR) scale, prebiotic, response surface modeling, magnitude estimation, equisweetness

\section{INTRODUCTION}

Functional product development provides an opportunity to contribute to the improvement of food quality and consumer health and well-being (Siró et al., 2008). Prebiotic ingredients such as inulin and oligofructose are good examples of this processed food category, being nondigestible fructans of interest in human nu-

Received October 14, 2013.

Accepted January 15, 2014

${ }^{1}$ Corresponding author: elisa.alimentos@gmail.com trition because of their ability to stimulate growth or activity of colonic bacteria that benefit the host and to inhibit growth of pathogens and harmful microorganisms (Saad et al., 2013). Addition of prebiotic ingredients to processed dairy foods is a reality (Isik et al., 2011; Arango et al., 2013; Cruz et al., 2013; Pimentel et al., 2013) and has been explored by the food industry.

The just-about-right (JAR) scale is an alternative method to acceptance tests that combines assessment of attribute intensity and hedonics by consumers, providing information on how consumers feel about a product and how much a sample deviates from an ideal point (Gacula et al., 2007). When applied together with response surface methodology (RSM; De Marchi et al., 2009; Cruz et al., 2010b; Mondragón-Bernal et al., 2010), the JAR scale can be a useful tool for optimizing the sensory quality of foods, as an optimal formulation derived from JAR responses maximizes consumer acceptance in the sense that it is the best possible formulation given a fixed set of ingredients.

When replacing sucrose with sweeteners, it is essential to have a clear understanding of which sweetener and what concentration of sweetener best match the sweetness intensity and characteristics of the equivalent product sweetened with sucrose. To substitute sucrose successfully, it is necessary to know sweetener concentrations that would be used and their sweetness equivalency related to sucrose. One of the most used methodologies to obtain this information is magnitude estimation and graphical presentation of the normalized results using Steven's power function (Cardoso and Bolini, 2007; Moraes and Bolini, 2010; Souza et al., 2011; De Souza et al., 2013; Esmerino et al., 2013).

Dairy desserts are appreciated by consumers and can be formulated with several ingredients as stabilizers. These ingredients interact, resulting in a wide variety of textures, flavors, and appearances (Verbeken et al., 2006), which, in turn, influence the nutritional, physical, and sensory characteristics, with direct effects on consumer acceptability (Arcia et al., 2011) However, to date, these published studies only evaluated the effect on the physicochemical and structural characteristics of the products. 
In this context, the main aim of this study was to optimize the formulation of a prebiotic chocolate dairy dessert formulated with different concentrations of prebiotics (inulin and fructooligosaccharides) and thickeners (xanthan and guar gum) using JAR responses and RSM, evaluating the extent to which the sensory properties are affected by adding these ingredients. A second aim of this work was to analyze the ideal and relative sweetness of the optimized prebiotic chocolate milk dessert sweetened with different artificial and natural sweeteners.

\section{MATERIALS AND METHODS}

\section{Ingredients and Preparation of Chocolate Dairy Dessert}

This study was developed in 2 stages. The first stage was to optimize formulation of the chocolate dairy dessert with the addition of prebiotics and gums. The next stage proceeded with the study of the replacement of sucrose by sweeteners.

The samples were produced with prebiotic Biofis Inufos (Siba Ingredientes, São Paulo, SP, Brazil), guar and xanthan gums (SweetMix, Sorocaba, Brazil), commercial skim milk powder (Molico, Nestlé, Araraquara, SP, Brazil), commercial UHT skim milk (Molico, Nestlé), cocoa powder (Garoto, Vila Velha, ES, Brazil), sucrose (União, Tarumâ, SP, Brazil), and light cream (Nestlé, Araçatuba, SP, Brazil). Chocolate milk dessert samples were sweetened with different high-intensity sweeteners and sucrose. The sweeteners were Neotame (NutraSweet, Chicago, IL; obtained from SweetMix), sucralose (SweetMix), stevia with 95\% rebaudioside (SweetMix), and aspartame (SweetMix).

The solid ingredients were mixed in a dry pan. The UHT skim milk was heated to $40^{\circ} \mathrm{C}$ and added to the mixture of solid ingredients under constant agitation. Subsequently, the temperature was increased to 90 $\pm 2^{\circ} \mathrm{C}$ for $3 \mathrm{~min}$ for pasteurization. The temperature was then reduced to $40^{\circ} \mathrm{C}$, cream was added, and the mixing continued for another $2 \mathrm{~min}$. The samples were put into plastic cups $(40 \mathrm{~mL})$, covered to avoid drying, and stored under refrigeration $\left(4 \pm 1^{\circ} \mathrm{C}\right)$ until sensory analysis.

\section{Optimization of Chocolate Dairy Dessert Formulation}

Nine chocolate milk desserts were formulated (Table 1) with different concentrations of prebiotic $(5.0,7.5$, and $10.0 \% \mathrm{wt} / \mathrm{wt})$ and gum $(0.10,0.20$, and $0.30 \%$ $\mathrm{wt} / \mathrm{wt})$. The concentrations of sucrose $(11.0 \% \mathrm{wt} / \mathrm{wt})$, skim milk powder $(10.0 \% \mathrm{wt} / \mathrm{wt})$, cocoa powder $(4.0 \%$ $\mathrm{wt} / \mathrm{wt})$, and cream $(25.0 \% \mathrm{wt} / \mathrm{wt})$ were kept constant. The UHT skim milk was added to $100 \%$ (wt/wt) of formulation. Previous studies determined the level of the ingredients used in this study.

Optimization Design. To determine the optimal concentration of guar and xanthan gums (in a 2:1 ratio) and prebiotics to be used in formulating the dairy dessert, an experiment was conducted using a completely randomized design, as shown in Table 2. The acceptance test was performed with 100 habitual consumers (32 male and 68 female) of dairy desserts, not trained and representative of the target public. An hedonic test was carried out using a continuous 9-cm unstructured line scale with the anchors "dislike extremely" and "like extremely" for the attributes of appearance, aroma, taste, texture, and overall impression. Sensitivity in defining consumer perception is greater with use of line scales than with the 9-point hedonic scale (Greene et al., 2006). In addition, a JAR scale (Desai et al., 2013) was applied to evaluate the ideal creaminess considered by the consumer panelists. Consumers were requested

Table 1. Experimental design composed of the variables in coded units and original values for experimental formulations (F) 1 through $9^{1}$

\begin{tabular}{|c|c|c|c|c|}
\hline \multirow[b]{2}{*}{ Experiment } & \multicolumn{2}{|c|}{$\begin{array}{l}\text { Codified levels } \\
\text { of the variables }\end{array}$} & \multicolumn{2}{|c|}{$\begin{array}{l}\text { Levels of the } \\
\text { original variables }\end{array}$} \\
\hline & $\mathrm{X}_{1}$ & $\mathrm{X}_{2}$ & G $(\%)$ & $\mathrm{P}(\%)$ \\
\hline $\mathrm{F} 1$ & +1 & -1 & 0.30 & 5.00 \\
\hline $\mathrm{F} 2$ & 0 & -1 & 0.20 & 5.00 \\
\hline F3 & -1 & -1 & 0.10 & 5.00 \\
\hline $\mathrm{F} 4$ & +1 & 0 & 0.30 & 7.50 \\
\hline F5 & 0 & 0 & 0.20 & 7.50 \\
\hline F6 & -1 & 0 & 0.10 & 7.50 \\
\hline F7 & +1 & +1 & 0.30 & 10.00 \\
\hline F8 & 0 & +1 & 0.20 & 10.00 \\
\hline F9 & -1 & +1 & 0.10 & 10.00 \\
\hline
\end{tabular}

${ }^{1}$ Where $\mathrm{X}_{1}=$ codified level of gum; $\mathrm{X}_{2}=$ codified level of prebiotic; $\mathrm{G}=$ gum content (\%); and $\mathrm{P}=$ prebiotic content (\%). 
Table 2. Ingredients and respective quantities $(\mathrm{g} / \mathrm{kg})$ used to produce 9 formulations (F1 to F9) of prebiotic chocolate dairy dessert

\begin{tabular}{|c|c|c|c|c|c|c|c|c|c|}
\hline Ingredient & \multicolumn{9}{|c|}{ Trial } \\
\hline Prebiotic & 50.0 & 50.0 & 50.0 & 75.0 & 75.0 & 75.0 & 100.0 & 100.0 & 100.0 \\
\hline Cocoa powder & 35.0 & 35.0 & 35.0 & 35.0 & 35.0 & 35.0 & 35.0 & 35.0 & 35.0 \\
\hline Sucrose & 100.0 & 100.0 & 100.0 & 100.0 & 100.0 & 100.0 & 100.0 & 100.0 & 100.0 \\
\hline Gum & 3.0 & 2.0 & 1.0 & 3.0 & 2.0 & 1.0 & 3.0 & 2.0 & 1.0 \\
\hline
\end{tabular}

to evaluate creaminess by placing a mark on a continuous 9-cm unstructured line scale from "not nearly creamy enough" $(-4.5)$ to "much too creamy" $(+4.5)$, and "just right" in the middle (corresponding to zero; Cadena and Bolini, 2012a; Esmerino et al., 2013).

Samples coded with 3 -digit numbers were presented monadically in a balanced block design to consumers in acrylic cups. Consumers received an evaluation form followed by the sample and were asked to evaluate the sample in relation to each attribute. Sessions were held at the Sensory Science and Consumer Study laboratory of the Faculty of Food Engineering/Department of Food and Nutrition (University of Campinas, Campinas, Brazil) in individual air-conditioned booths in a single session; taste-free water and biscuits were provided for palate cleansing. Each consumer's decisions were based solely on the sensory characteristics of the desserts, because product information and formulation were not provided.

Statistical Analysis. The acceptability data were analyzed by mixed ANOVA considering sample and consumers as sources of variation (sample as fixed effect and consumer as random effect), and Tukey's honestly significant difference (HSD) average test. Analyses were carried out using SAS software (version 9.1.2; SAS Institute, 2009) at a 5\% significance level.

To relate the studied variables to concentration, data were subjected to a multivariate regression analysis and fitted to a second-order model equation provided in the design given by RSM (Equation [1]):

$$
\begin{gathered}
\mathrm{Y}=\mathrm{B}_{0}+\mathrm{B}_{1} \mathrm{X}_{1}+\mathrm{B}_{2} \mathrm{X}_{2}+\mathrm{B}_{11} \mathrm{X}_{1}{ }^{2}+\mathrm{B}_{22} \mathrm{X}_{2}{ }^{2} \\
+\mathrm{B}_{12} \mathrm{X}_{12}+\text { error }
\end{gathered}
$$

where $\mathrm{Y}$ is the studied variable; $\mathrm{B}_{0}$ is the intercept (constant); $\mathrm{B}_{1}, \mathrm{~B}_{2}$ are the linear effects; $\mathrm{B}_{11}, \mathrm{~B}_{22}$ are the quadratic effects; $B_{12}$ is the interaction effects; $X_{1}$ is the gum content; and $\mathrm{X}_{2}$ is the prebiotic content.

To analyze data obtained with the JAR scale, the percentage of consumers rating the creaminess of sample in each point of the scale was first calculated.
Second, the approach proposed by Gacula et al. (2007) was followed, estimating deviations below and above point 0 on the JAR scale. Individual scale scores -4.5 , $-2.25,0,2.25,4.5$ were transformed to $-2,-1,0,1$, 2 , respectively. Two groups of data emerged from this calculation, one for consumers who felt that the sample lacked the attribute (below JAR) and another for those consumers who felt the product exceeded the attribute (above JAR). For each sample, the mean of values below JAR point 0 corresponded to the negative deviation value (too little of the attribute) and the mean of values above JAR point 0 corresponded to the positive deviation value (too much of the attribute). These analyses were carried out using the software $\mathrm{R}$ ( $\mathrm{R}$ Development Core Team, 2012) and the rsm package. In addition, penalty analysis (Drake et al., 2011) was performed to reach conclusions related to the effects of creaminess on overall liking, identifying decreases in acceptability associated with this sensory attribute not at optimal levels in a product. This analysis was performed in XLSTAT 2013 (Addinsoft, Paris, France).

\section{Ideal and Equivalent Sweetness of Chocolate Dairy Dessert}

The optimized formulation in the previous step was tested using different levels of sucrose and sweeteners. The concentrations of sucrose and sweeteners varied, and UHT skim milk was added to $100 \%$ (wt/wt) of the formulation.

Sucrose Ideal Sweetness. To reach the equivalent sweetness for various sweeteners compared with sucrose, sensory evaluations were conducted at various stages. Determining the optimal concentration of sucrose $(\%)$ to be added to the processed chocolate dairy dessert was performed by means of an affective test, using the JAR scale (Esmerino et al., 2013). The samples were sweetened with 5 concentrations of sucrose: $6.0,8.0$, $10.0,12.0$, and $14.0 \%$ (wt/wt) to determine the ideal level of sucrose in chocolate milk dessert.

The samples were evaluated in individual booths in the Sensory Science and Consumer Study Labora- 
tory, Department of Food and Nutrition (University of Campinas, Campinas, Brazil). Sample presentation was monadic in acrylic cups coded with 3-digit numbers, using a balanced complete block design (Walkeling and MacFie, 1995). The consumers were served $30 \mathrm{~g}$ of each dessert sample containing different sucrose concentrations and requested to evaluate the sweetness using the JAR scale anchored with "not nearly sweet enough" $(-4)$ to "much too sweet" $(+4)$, with "just right" in the middle (corresponding to zero). A total of 100 consumers of dairy dessert (63 women and 37 men with mean age of $33 \mathrm{yr}$ recruited on the University of Campinas campus through posters and e-mail lists) evaluated the samples.

The sensory evaluation results were analyzed by histograms with the sensory response distribution (\%) with respect to the sucrose concentration added to the dessert, and also by simple linear regression between hedonic values and sucrose concentration, as suggested by Vickers (1988).

Equivalent Sweetness of High-Intensity Sweeteners. Panelists were selected and trained to evaluate the equivalent sweetness of sweeteners. A series of triangular tests with 30 recruited tasters was held to select panelists, and the Wald sequential analysis was applied to check the discrimination ability of each individual. The assessors had to identify which of 3 samples served was different from the other two. Tasters were selected or rejected according to the number of correct tests analyzed in the triangular test. Fifteen assessors, 10 women and 5 men with mean age of $34 \mathrm{yr}$, were selected for the determination of the equi-sweet concentrations of the different sweeteners.

Panelists preselected by the Wald sequential analysis were trained to use magnitude scales with different sweetness potency standards. The training was based on an explanation of the methodology and the correct use of the magnitude scale.

Determination of Equivalent Sweetness and Sweetener Potency. The relative sweetness of high intensity sweeteners was measured using the magnitude estimation method, which allows a direct quantitative measurement of the subjective intensity of sweetness. The dessert samples were presented according to a bal- anced complete block design followed by a reference sample sweetened with sucrose at the ideal concentration, with which the sweetness equivalence was determined. The reference sample was designated to have an intensity of 100 , followed by a random series of samples with greater and lesser intensities compared with the reference intensity. The assessor had to estimate the sweetness intensity of the unknown samples relative to the reference. For example, if a sample was twice as sweet as the reference, it would receive an intensity of 200, whereas if it were half as sweet, the intensity would be 50, and so on. Assessors were instructed not to rate the sample intensity as 0 .

To determine the equivalent sweetness of sweeteners relative to sucrose, the series of concentrations presented in Table 3 was used. For data analysis, the estimated sweetness magnitude values of sucrose and sweeteners were converted into geometric averages, and these values were set to a logarithmic scale. The logarithmic concentration $(\boldsymbol{C})$ values used for each sweetener were plotted against the logarithmic values of the estimated magnitudes for the stimuli perceived as sensations $(\boldsymbol{S})$, and a linear regression of points was obtained, such that a simple power function $S=\mathrm{a} \cdot C^{\mathrm{n}}$ described the data, where a and $\mathrm{n}$ are the parameters to be estimated.

The equivalent concentration of each sweetener was calculated using the equation obtained for the prebiotic chocolate dairy dessert with sucrose; in place of $C$ (sweetener concentration), the value of $8 \%$ (wt/wt) was assigned, which is the ideal sweetness of sucrose. Thus, the value of $S$ (sucrose sweetness perceived) was mathematically estimated. The $S$ values for sucrose were substituted into the other equations (for other sweeteners) and thus the optimal concentration of each sweetener was determined in reference to the equivalent prebiotic chocolate dairy dessert with $8 \%$ sucrose.

\section{RESULTS AND DISCUSSION}

\section{Consumer Acceptability of Chocolate Dairy Desserts}

The sensory attributes evaluated through the acceptance test are presented in Table 4. Significant dif-

Table 3. Concentrations of the sweeteners used for determining the equivalent sweetness in processed prebiotic chocolate dairy dessert to $8 \%$ of sucrose

\begin{tabular}{|c|c|c|c|c|c|}
\hline \multirow{2}{*}{$\frac{\text { Sweetener }}{\text { Sucrose }}$} & \multicolumn{5}{|c|}{ Concentration for the equivalent sweetness (\%) } \\
\hline & 6.0000 & 8.0000 & 10.0000 & 12.0000 & 14.0000 \\
\hline Sucralose & 0.0063 & 0.0100 & 0.0160 & 0.0256 & 0.0410 \\
\hline Aspartame & 0.0200 & 0.0340 & 0.0550 & 0.0880 & 0.1408 \\
\hline Stevia & 0.0391 & 0.0625 & 0.1000 & 0.1600 & 0.2560 \\
\hline Neotame $^{1}$ & 0.0070 & 0.0010 & 0.0017 & 0.0027 & 0.0041 \\
\hline
\end{tabular}

${ }^{1}$ NutraSweet (Chicago, IL). 
Table 4. Means of the attributes evaluated by 100 consumers (9-cm unstructured line scale)

\begin{tabular}{|c|c|c|c|c|c|}
\hline \multirow[b]{2}{*}{ Sample } & \multicolumn{5}{|c|}{ Attribute } \\
\hline & Appearance & Aroma & Taste & Texture & $\begin{array}{c}\text { Overall } \\
\text { impression }\end{array}$ \\
\hline F1 & $6.26^{\mathrm{d}}$ & $7.02^{\mathrm{b}}$ & $6.69^{\mathrm{f}}$ & $4.62^{\mathrm{f}}$ & $6.31^{\mathrm{e}}$ \\
\hline $\mathrm{F} 2$ & $8.03^{\mathrm{c}}$ & $7.02^{\mathrm{b}}$ & $7.30^{\mathrm{d}}$ & $6.93^{\mathrm{c}}$ & $7.46^{\mathrm{b}}$ \\
\hline F3 & $2.70^{\mathrm{f}}$ & $6.43^{\mathrm{d}}$ & $7.93^{\mathrm{c}}$ & $5.86^{\mathrm{e}}$ & $5.92^{\mathrm{f}}$ \\
\hline $\mathrm{F} 4$ & $8.28^{\mathrm{b}}$ & $6.83^{\mathrm{c}}$ & $7.16^{\mathrm{e}}$ & $6.46^{\mathrm{d}}$ & $7.35^{\mathrm{c}}$ \\
\hline F5 & $8.63^{\mathrm{a}}$ & $7.95^{\mathrm{a}}$ & $8.45^{\mathrm{a}}$ & $7.67^{\mathrm{a}}$ & $8.27^{\mathrm{a}}$ \\
\hline $\mathrm{F} 6$ & $3.71^{\mathrm{e}}$ & $7.01^{\mathrm{bc}}$ & $8.11^{\mathrm{b}}$ & $7.14^{\mathrm{b}}$ & $6.65^{\mathrm{d}}$ \\
\hline F7 & $3.60^{\mathrm{e}}$ & $5.01^{\mathrm{e}}$ & $5.55^{\mathrm{g}}$ & $3.89^{\mathrm{g}}$ & $3.39^{f}$ \\
\hline F8 & $4.01^{\mathrm{e}}$ & $5.63^{\mathrm{de}}$ & $5.91^{\mathrm{g}}$ & $4.51^{\mathrm{f}}$ & $4.01^{\mathrm{f}}$ \\
\hline F9 & $2.55^{\mathrm{f}}$ & $4.77^{\mathrm{e}}$ & $5.78^{\mathrm{g}}$ & $4.60^{\mathrm{f}}$ & $2.99^{f}$ \\
\hline
\end{tabular}

${ }^{\mathrm{a}-\mathrm{g}}$ Values with different letters within a column are significantly different according to Tukey test $(P<0.05)$.

ferences between samples $(\alpha=0.05 ; P \leq 0.05)$ were detected for all attributes, indicating that enrichment with prebiotic and gum caused changes in the sensory characteristics of chocolate dairy desserts. Similar results were found in dairy desserts formulated with different levels of carrageenan, cacao, and polydextrose (Ares et al., 2010), suggesting the importance of formulating desserts with ingredients that influence the texture of the product.

As shown in Table 4, addition of $7.5 \%$ prebiotic and $0.2 \%$ gum caused a significant increase in appearance, aroma, taste, texture, and overall acceptability of chocolate dairy desserts, indicating that consumers perceived positively the changes in these attributes introduced by these levels of prebiotics and gum. For example, overall liking ranged from 6.65 to $8.27(P<0.05)$, whereas taste and texture had values ranging from 7.16 to 8.11 and from 6.46 to 7.67 , respectively.

Addition of $10.0 \%$ prebiotic, independent of the concentration of added gum, caused a significant reduction in appearance, aroma, taste, texture, and overall acceptability of chocolate dairy desserts, indicating that consumers perceived negatively the changes in these attributes introduced by the higher levels of prebiotics. The overall acceptability of the dairy dessert with $7.5 \%$ prebiotic and $0.20 \%$ gum was 8.27 , but it decreased to 4.01 when $10.0 \%$ prebiotic was added. Muñoz et al. (1992) considered an acceptability score of 6.0 in a 9 -point hedonic scale (the first score in the liking category) as the lower limit of acceptability for a commercial product. Therefore, by this criterion, a chocolate dairy dessert containing $10.0 \%$ prebiotics would not be acceptable. These findings indicate that development of processed food with added prebiotic ingredients should be carefully evaluated by sensory methodologies (Cruz et al., 2010a).

As shown in Table 4, the addition of $0.10 \%$ (wt/ wt) gum, independent of the concentration of added prebiotic, caused a significant reduction in appear- ance, aroma, taste, texture, and overall acceptability of chocolate dairy desserts, indicating that consumers perceived negatively the changes in these attributes introduced by lower levels of gum.

\section{Creaminess Suitability Assessed by Consumers}

Creaminess in dairy desserts is a sensory attribute extremely valued by consumers (Antmann et al., 2011a,b). The JAR scale was used to evaluate the creaminess of a chocolate dairy dessert to determine how much each sample varied from or approached the desirable level for this product. The percentage of consumers that considered creaminess to be JAR varied greatly among samples, from $3.75 \%$ for sample $9(0.10 \% \mathrm{wt} / \mathrm{wt}$ gum, $10.0 \% \mathrm{wt} / \mathrm{wt}$ prebiotic) to $48.75 \%$ for sample $5(0.20 \%$ wt/wt gum; $7.5 \%$ wt/wt prebiotic; Table 5$)$. The model explaining the relationship between the percentage of consumers considering creaminess as JAR (\% Consumer JAR) and sample composition (where $\mathrm{P}=$ prebiotic and $\mathrm{G}=$ gum) was as follows (Equation [2]):

$$
\begin{gathered}
\text { \% Consumer JAR }=-138.61+525.00 \mathrm{G}+36.75 \mathrm{P} \\
-1.583 .33 \mathrm{G}^{2}-2.83 \mathrm{P}^{2}+15 \mathrm{GP} .
\end{gathered}
$$

Both prebiotic and gum concentrations significantly affected consumer assessment of creaminess, showing an inverted U-shaped relationship within the concentration ranges considered in this study (Figure 1). The most adequate creaminess corresponded to samples with intermediate levels of prebiotic and gum. For consumers who did not consider creaminess adequate but considered it as "too much" or "too little," creaminess deviation from the JAR was calculated for each sample (Table 5). Deviation values depended on both gum and prebiotic contents. The addition of prebiotic at high concentrations $(>7.5 \%)$ resulted in samples with too much creaminess, independent of gum concentration 
Table 5. Percentage of consumers considering creaminess as just about right (JAR) and deviation (positive and negative values) for each dairy dessert sample

\begin{tabular}{lccc}
\hline & & \multicolumn{2}{c}{ Deviation $^{1}$} \\
\cline { 3 - 4 } Sample & $\begin{array}{c}\text { Consumers considering } \\
\text { creaminess as JAR (\%) }\end{array}$ & Too little & Too much \\
\hline F1 & 8.75 & -0.660 & 0.796 \\
F2 & 35.00 & -0.379 & 0.570 \\
F3 & 17.50 & -0.834 & 0.717 \\
F4 & 25.00 & -0.796 & 0.767 \\
F5 & 48.75 & -0.316 & 0.706 \\
F6 & 20.00 & -0.388 & 0.397 \\
F7 & 10.00 & 0.000 & 0.672 \\
F8 & 6.25 & 0.000 & 1.079 \\
F9 & 3.75 & 0.000 & 1.229 \\
\hline
\end{tabular}

${ }^{1}$ Based on 9-cm JAR scale: "not nearly creamy enough" $=-4.5$, "much too creamy" $=+4.5$, and "just about right" in the middle (corresponding to zero).

(samples 7, 8, and 9) because the term associated with the interaction between the effects of both ingredients was not significant. Penalty analysis values ranged from -0.241 (sample 7) to 0.054 (sample 3); however, penalty analysis values did not differ significantly $(P>$ 0.05), suggesting that, at the levels studied, the overall acceptance of the prebiotic dairy desserts was not influenced by the creaminess level. It is interesting to note that no samples were considered "excellent" from a sensory standpoint.



Figure 1. Relation between percentage of consumers considering creaminess of samples as a function of the just-about-right (JAR) scale, gum concentration (\% wt/wt), and prebiotic concentration $(\%$ $\mathrm{wt} / \mathrm{wt}$ ). Color version available in the online PDF.
Arcia et al. (2011) evaluated the thickness of prebiotic dairy desserts in relation to sucrose and inulin contents. They observed that the effect of inulin depended on sucrose concentration and vice versa. González-Tomás et al. (2009) studied an inulin-enriched dairy dessert and showed that adding $7.5 \%$ inulin (concentration close to that found to be optimal in this study) of different average chain lengths can give rise to products with different rheological behaviors and different sensory characteristics.

The concentration ranges of each ingredient for maximum acceptability in relation to ideal creaminess were determined using contour plots of the obtained model. According to Figure 1, maximum acceptability values were obtained with concentrations of 7.21 and $0.19 \%$ for prebiotic and gum, respectively. These values are close to those obtained for overall impression in the acceptance test and confirm results of a previous study that compared JAR scales and attribute liking to evaluate appropriate sensory attributes of milk desserts (Ares et al., 2009). The gum and prebiotic concentrations for ideal creaminess and overall acceptability were $0.20 \%$ (wt/wt) and $7.5 \%$ (wt/wt), respectively; therefore, these concentrations were used in the subsequent tests.

\section{Ideal Concentration of Sucrose}

According to the consumer evaluation, a significant difference (at a $5 \%$ probability by an $F$-test) was observed between samples sweetened with different concentrations of sucrose. Therefore, a regression model was adjusted to relate ideal sweetness to sucrose concentrations of prebiotic chocolate dairy dessert samples. The linear model showed the best data fit $\left(\mathrm{R}^{2}\right.$ $=0.91$; Figure 2). Through the regression equation, the amount of sucrose to be added to the prebiotic chocolate dairy dessert was calculated and found to be $8.13 \%$. Therefore, in subsequent experiments, a concentration of $8.0 \%$ sucrose was chosen.

Indeed, the ideal concentration of sucrose varies with the type of product. Moraes and Bolini (2010) determined that $9.5 \%$ was the ideal concentration of sucrose in instant coffee beverages, $10 \%$ sucrose was determined as ideal by Cardoso and Bolini (2007) for peach nectar, $7 \%$ sucrose was ideal for mango nectar Cadena and Bolini (2012), whereas Souza et al. (2011) found a greater value (17\% sucrose) in Petit Suisse cheese, which has a semi-solid structure like our chocolate dairy dessert. In the case of the chocolate dairy dessert in the current study with addition of the prebiotic fructooligosaccharides, the need to add sucrose decreases, because the prebiotic itself has sweetening power, although in lesser amounts than sucrose. According to Villegas et al. (2010), fructooligosaccharide 


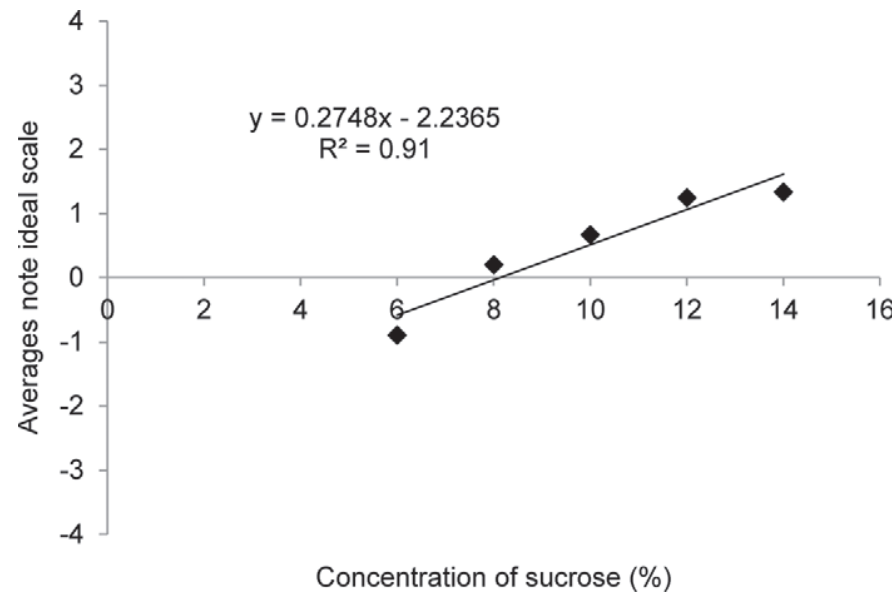

Figure 2. Graphic representation of the regression equation and coefficient of determination of average of the notes given by the sweetness ideal scale as a function of sucrose concentration in prebiotic chocolate dairy dessert.

products enhance flavor and sweetness and can be used to partly replace sucrose.

\section{Determination of Equivalent Sweetness}

The logarithmic values of concentrations $(C)$ for sucrose and for each sweetener were plotted against the logarithmic values of the estimated magnitudes (appropriately normalized) for stimuli perceived as sensations $(S)$. A linear regression of points obtained for sucrose and the various sweeteners was then made, and a straight-line equation was obtained for each of the sweeteners (Figure 3). These results allowed us to determine the concentrations of each sweetener equivalent to the sucrose concentration $(8.0 \% \mathrm{wt} / \mathrm{wt})$ in the prebiotic chocolate dairy dessert.

Table 6 shows the results for the angular coefficient (A), intercept on the ordinate (n), linear coefficient of determination $\left(\mathrm{R}^{2}\right)$, and the power function of each sweetener; Figure 3 shows the relationship between sweetness intensities and concentrations on a logarithmic scale.

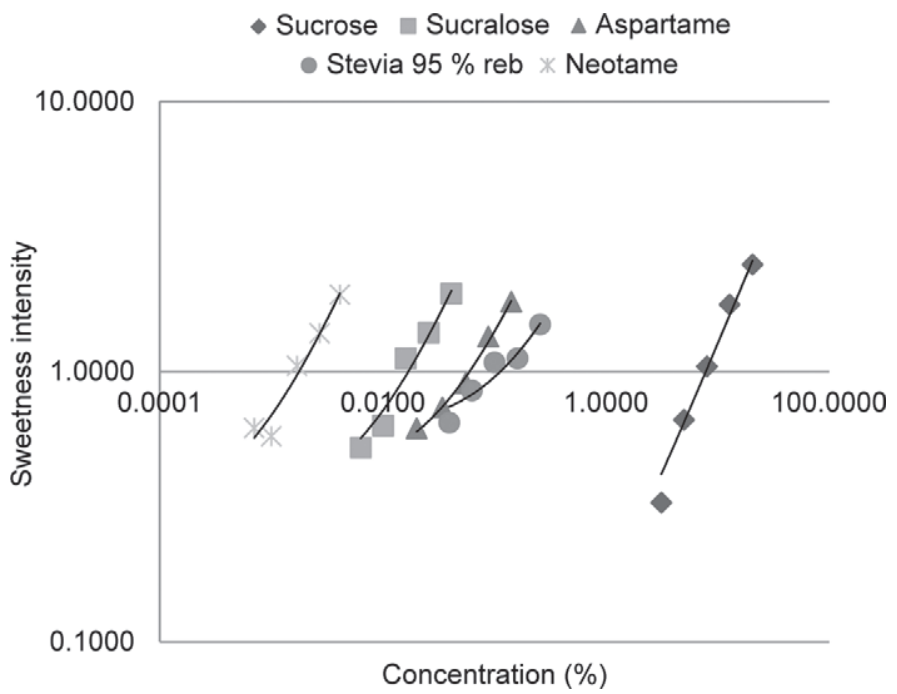

Figure 3. Results of the linearized power function for prebiotic chocolate dairy dessert sweetened with sucrose, sucralose, aspartame, Neotame (NutraSweet, Chicago, IL), and stevia with $95 \%$ rebaudioside. The $\mathrm{x}$-axis shows the concentration of the sweeteners (\%) and the $y$-axis shows the values of the estimated magnitudes appropriately normalized.

Using the position of the curves observed in the graph shown in Figure 3, it is possible to identify the ratio of the sweetness of various sweeteners used. The positioning of the curves indicates the sweetening intensity of each sweetener. The sucrose curve is distant from the others, indicating that much higher concentrations of sucrose are needed to achieve the same sweetness sensation. Neotame is furthest from sucrose, indicating that a lower concentration of Neotame is required to express the same sweetness as sucrose.

Neotame [N-( $N$-(3,3-dimethylbutyl)-L- $\alpha$-aspartyl)-Lphenylalanine 1-methyl ester] is a high-potency sweetener and flavor enhancer that is currently approved for use in 69 countries worldwide. This zero-calorie sweetener has a clean, sweet taste with no undesirable taste characteristics, and it is functional and stable in a wide array of beverages and foods. Given its high potency, Neotame has proven to be one of the most

Table 6. Angular coefficient (A), intercept on the ordinate (n), linear coefficient of determination $\left(\mathrm{R}^{2}\right)$, and power function of the results to determine the equivalent sweetness of each sweetener in relation to $8 \%$ sucrose concentration of prebiotic chocolate dairy dessert

\begin{tabular}{lcrll}
\hline Sweetener & $\mathrm{A}$ & $\mathrm{n}$ & \multicolumn{1}{c}{$\mathrm{R}^{2}$} & Power function $^{1}$ \\
\hline Sucrose & 1.0736 & -0.9696 & 0.9859 & $S=0.1072 \cdot C^{1.0736}$ \\
Sucralose & 0.7308 & 1.3118 & 0.9764 & $S=20.5021 \cdot C^{0.7308}$ \\
Aspartame & 0.5678 & 0.7193 & 0.9702 & $S=5.2396 \cdot C^{0.5678}$ \\
Stevia & 0.4154 & 0.4154 & 0.9603 & $S=2.6025 \cdot C^{0.4154}$ \\
Neotame $^{2}$ & 0.7059 & 1.9597 & 0.9483 & $S=91.1381 \cdot C^{0.7059}$ \\
\hline
\end{tabular}

${ }^{1}$ Where $S=$ logarithmic values of the estimated magnitudes for the stimuli perceived as sensations; $C=\operatorname{loga}-$ rithmic concentration of each sweetener.

${ }^{2}$ NutraSweet (Chicago, IL). 
cost-effective sweeteners on the market (Mayhew et al., 2012). It is approved for use in processed foods in the United States and its principal utility is in reducedcalorie products, in which up to $25 \%$ calorie reduction can be achieved without significant decrement in taste quality. In the United States, Neotame has an acceptable daily intake (ADI) of $0.3 \mathrm{mg} / \mathrm{kg}$ of BW (DuBois and Prakash, 2012).

From the power function of each sweetener, we were able to calculate the concentration equivalent of each sweetener and its potency compared with sucrose. The concentrations of each sweetener were calculated in equivalence of the ideal sweetness of sucrose in prebiotic chocolate dairy dessert $(8.0 \%)$ and the results are shown in Table 7 . No data were found in the literature on the use of sweeteners in processed dairy dessert. However, comparing the concentration values of sweeteners in other products, it appears that our values were within the range of values reported previously (Cadena and Bolini, 2012; Esmerino et al., 2013).

From Table 7, it can be seen that Neotame required the lowest quantity to provide sweetness equivalent to $8.0 \%$ sucrose in prebiotic chocolate dairy dessert, followed by sucralose, aspartame, and stevia. Thus, Neotame had the highest sweetening power, being 5,000 times sweeter than sucrose. Therefore, to substitute Neotame for sucrose in a prebiotic chocolate dairy dessert with $8.0 \%$ sucrose, $0.0016 \%$ Neotame would be required. Nofre and Tinti (2000) reported that Neotame is 6,000 to 10,000 times sweeter than sucrose.

Sucralose presented a sweetness power of 500, a value slightly below the values of 636 in instant coffee and 599 in ground roasted coffee reported by Moraes and Bolini (2010) and the value of 629 found by Cardoso and Bolini (2007) in peach nectar. Souza et al. (2011) found a value of 261 in strawberry-flavored Petit Suisse cheese. Stevia with $95 \%$ rebaudioside was 80 times sweeter than sucrose, having lower values compared with instant coffee and mango nectar (100 and 134, respectively; Moraes and Bolini, 2010; Cadena and Bolini, 2012). Stevioside [19-O- $\beta$-glucopyranosyl-13O- $\beta$ glucopyranosyl $(1,2)-\beta$-glucopyranosyl-steviol] is a mixture of active components of sweet taste. With high

Table 7. Equivalent concentration and potency of the sweeteners, corresponding to the $8.0 \%$ sucrose concentration in prebiotic chocolate dairy dessert

\begin{tabular}{lcc}
\hline Sweetener & $\begin{array}{c}\text { Concentration equivalent } \\
\text { to } 8.0 \% \text { sucrose }\end{array}$ & $\begin{array}{r}\text { Sweetener potency } \\
\text { at } 8.0 \% \text { sucrose }\end{array}$ \\
\hline Sucralose & 0.0160 & 500.00 \\
Aspartame & 0.0540 & 148.15 \\
Stevia $^{1}$ & 0.1000 & 80.00 \\
Neotame $^{1}$ & 0.0016 & $5,000.00$ \\
\hline
\end{tabular}

${ }^{1}$ NutraSweet (Chicago, IL). purity and zero calories, stevia is of great interest to the global food industry (Carakostas et al., 2012).

The differences between the concentration values of sweeteners found in our prebiotic chocolate dairy dessert and the values found in the literature can be explained by the difference in the types of product and in their optimal concentration of sucrose. The perception of the sweetness of a sweetener is influenced by several factors such as type and concentration of the sweetener, dispersion medium (aqueous, lipidic, or other food ingredients), synergy of other components present in the food matrix, temperature, $\mathrm{pH}$, and other properties (Wiet and Beyts, 1992). It is also important to verify the difference in sweetening power when a product is more complex; that is, when other ingredients, such as fat, proteins, acids, or carbohydrates, are involved. When a sweetener (or a combination of sweeteners) is added to a food product, it is necessary to consider the various interactions among the sweeteners and the food ingredients that could alter the sweetener's potency. The ideal sweetener should present a similar profile to sucrose, the ingredient most used to create sweet taste in processed foods.. In addition, for economic reasons, only a small amount of sweeteners should be added during food formulation. In this regard, sucralose and Neotame meet these requirements, as they presented the highest potency values (500.00 and 5,000.00, respectively), requiring addition of just 0.016 and $0.0016 \%$ (wt/wt) to achieve the same perception of sweet taste as that obtained with sucrose. Therefore, these options are available to the dairy industry to produce prebiotic dairy desserts with reduced caloric value.

Overall, our findings are valuable for the functional dairy industry, because it was possible to determine and optimize the concentration of prebiotics from a sensory point of view. A food matrix with an added prebiotic ingredient also contributes to global sweetness because of the sweetening power of fructooligosaccharides. Future research should include sensory profiling by a trained panel (Cadena et al., 2012; Morais et al., 2014, ) as well as consumer profiling techniques (Santos et al., 2012; Cruz et al., 2013). Dynamic sensory methodologies, such as a time-intensity method, would also be useful (Cadena and Bolini, 2011; Morais et al., 2013). Sweeteners present different characteristics in different types of foods and beverages that influence the perception of sweetness and the product's acceptance; these factors must be considered when replacing sucrose.

\section{CONCLUSIONS}

The addition of prebiotic and gum to chocolate dairy desserts affected acceptability. The effect depended not only on the concentration of added prebiotic but also 
on that of gum. We established a relationship between the acceptability of chocolate dairy dessert and its composition. Our models predicted acceptability and ideal creaminess in terms of the concentrations of prebiotic and gum. This information will be useful in designing new products with nutritional and sensory characteristics that meet consumer demand. The concentration of sucrose considered ideal in our prebiotic chocolate dairy dessert was $8.0 \%$. The magnitude estimation method allowed us to determine the sweetness equivalence of sucralose, aspartame, stevia, and Neotame compared with $8.0 \%$ sucrose; the concentrations of each that should be added to processed dessert were 0.0160 , $0.0540,0.100$, and $0.0016 \%$, respectively. Neotame was found to be the strongest sweetener and stevia the weakest. The development of dairy products with sugar substitutes must consider the acceptability of the product to consumers. Each sweetener presents a characteristic sensory profile and must be used according to its power of sweetness and consumer acceptability.

\section{ACKNOWLEDGMENTS}

The present study was carried out with the support of the Brazilian National Research Council (CNPq; Brasília, DF, Brazil).

\section{REFERENCES}

Antmann, G., G. Ares, A. Salvador, P. Varela, and S. M. Fiszman 2011a. Exploring and explaining creaminess perception: Consumer's underlying concepts. J. Sens. Stud. 26:40-47.

Antmann, G., G. Ares, P. Varela, A. Salvador, B. Coste, and S. M. Fiszman. 2011b. Consumers' creaminess concept perception: A cross cultural study in three Spanish-speaking countries. J. Texture Stud. 42:50-60.

Arango, O., A. J. Trujillo, and M. Castillo. 2013. Influence of fat replacement by inulin on rheological properties, kinetics of rennet milk coagulation, and syneresis of milk gels. J. Dairy Sci. 96:1984-1996.

Arcia, P. L., E. Costell, and A. Tárrega. 2011. Inulin blend as prebiotic and fat replacer in dairy desserts: Optimization by response surface methodology. J. Dairy Sci. 94:2192-2200.

Ares, G., C. Barreiro, and A. Gimenéz. 2009. Comparison of attribute liking and JAR scales to evaluate the adequacy of sensory attributes of milk desserts. J. Sens. Stud. 24:664-667.

Ares, G., R. Deliza, C. Barreto, A. Gimenéz, and A. Gámbarro. 2010. Comparison of two sensory profiling techniques based on consumer perception. Food Qual. Prefer. 21:417-426.

Cadena, R. S., and H. M. A. Bolini. 2011. Time-intensity analysis and acceptance test for traditional and light vanilla ice cream. Food Res. Int. 54:677-683.

Cadena, R. S., and H. M. A. Bolini. 2012. Ideal and relative sweetness of high intensity sweeteners in mango nectar. Int. J. Food Sci. Technol. 47:991-996.

Cadena, R. S., A. G. Cruz, J. A. F. Faria, and H. M. A. Bolini. 2012. Reduced fat and sugar vanilla ice creams: Sensory profiling and external preference mapping. J. Dairy Sci. 95:4842-4850.

Carakostas, M., I. Prakash, A. D. Kinghorn, C. D. Wu, and D. D Soerjato. 2012. Steviol glycosides: Neotame. Pages 159-180 in Alternative Sweeteners. 4th ed. L. O'Brien Nabors, ed. CRC Press, Boca Raton, FL.
Cardoso, J. M. P., and H. M. A. Bolini. 2007. Different sweeteners in peach nectar: Ideal and equivalent sweetness. Food Res. Int. 40:1249-1253.

Cruz, A. G., R. S. Cadena, E. H. M. Walter, A. M. Motazavian, D. Granato, J. A. F. Faria, and H. M. A. Bolini. 2010a. Sensory analysis: Relevance for prebiotic, probiotic, and synbiotic product development. Comp. Rev. Food Sci. Safety 9:358-373.

Cruz, A. G., R. N. Cavalcanti, L. M. R. Guerreiro, A. S. Sant'ana, L. C. Nogueira, C. A. F. Oliveira, R. Deliza, R. L. Cunha, J. A. F. Faria, and H. M. A. Bolini. 2013. Developing a prebiotic yogurt: Rheological, physico-chemical and microbiological aspects and adequacy of survival analysis methodology. J. Food Eng. 114:323-330.

Cruz, A. G., J. A. F. Faria, E. H. M. Walter, R. R. Andrade, R. N. Cavalcanti, C. A. F. Oliveira, and D. Granato. 2010b. Processing optimization of probiotic yogurt containing glucose oxidase using response surface methodology. J. Dairy Sci. 93:5059-5068.

De Marchi, R., M. R. McDaniel, and H. M. A. Bolini. 2009. Formulating a new passion fruit juice beverage with different sweetener systems. J. Sens. Stud. 24:698-711.

De Souza, V. R., V. R. Pereira, A. C. M. Pinheiro, H. M. A. Bolini, S. V. Borges, and F. Queiroz. 2013. Analysis of various sweeteners in low-sugar mixed fruit jam: Equivalent sweetness, timeintensity analysis and acceptance test. Int. J. Food Sci. Technol. 48:1541-1548

Desai, N. T., L. Shepard, and M. A. Drake. 2013. Sensory properties and drivers of liking for Greek yogurts. J. Dairy Sci. 96:74547466 .

Drake, S. L., K. Lopetcharat, and M. A. Drake. 2011. Salty taste in dairy foods: Can we reduce the salt? J. Dairy Sci. 94:636-645.

DuBois, G. E., and I. Prakash. 2012. Non-caloric sweeteners: Sweetness modulators and sweetener enhancers. Annu. Rev. Food Sci Technol. 3:353-380.

Esmerino, E. A., A. G. Cruz, E. P. R. Pereira, J. B. Rodrigues, J. A F. Faria, and H. M. A. Bolini. 2013. The influence of sweeteners in probiotic Petit Suisse cheese in concentrations equivalent to that of sucrose. J. Dairy Sci. 96:5512-5521.

Gacula, M., S. Rutenbeck, L. Pollack, A. Ressurection, and H. Moskowitz. 2007. The just about right intensity scale: Functional analysis and relation to hedonic. J. Sens. Stud. 22:194-211.

González-Tomás, L., S. Bayarri, J. Coll-Marqués, and E. Costell. 2009. Flow behaviour of inulin-enriched dairy desserts: Influence of inulin average chain length. Int. J. Food Sci. Technol. 44:1214-1222.

Greene, J. L., K. J. Bratka, M. A. Drake, and T. H. Sanders. 2006. Effectiveness of category and line scales to characterize consumer perception of fruity fermented flavor in peanuts. J. Sens. Stud. $26: 146-154$.

Isik, U., D. Boyacioglu, E. Capanoglu, and D. N. Erdil. 2011. Frozen yogurt with added inulin. J. Dairy Sci. 94:1647-1656.

Mayhew, D. A., B. I. Meyers, W. W. Stargel, C. P. Comer, S. E. Andress, and H. H. Butchko. 2012. Neotame. Pages 133-150 in Alternative Sweeteners. 4th ed. L. O'Brien Nabors, ed. CRC Press, Boca Raton, FL.

Mondragón-Bernal, O., M. I. Rodrigues, H. M. A. Bolini, and F. Maugeri. 2010. Optimization of symbiotic fermented food from hydrosoluble soy extract applying experimental design and sensory analysis techniques. J. Sens. Stud. 25:371-389.

Moraes, P. C. T. B., and H. M. A. Bolini. 2010. Different sweeteners in beverages prepared with instant and roasted ground coffee: Ideal and equivalent sweetness. J. Sens. Stud. 25:1-11.

Morais, E. C., A. G. Cruz, and H. M. A. Bolini. 2013. Gluten-free bread: Multiple time-intensity analysis, physical characterisation and acceptance test. Int. J. Food Sci. Technol. 48:2176-2184.

Morais, E. C., A. G. Cruz, J. A. F. Faria, and H. M. A. Bolini. 2014. Prebiotic gluten-free bread: Sensory profiling and drivers of liking. Lebenson. Wiss. Technol. 55:248-254.

Muñoz, A. M., V. G. Civillea, and B. T. Carr. 1992. Sensory Evaluation in Quality Control. Van Nostrand Reinhold, New York, NY.

Nofre, C., and J. M. Tinti. 2000. Neotame: Discovery, properties, utility. Food Chem. 69:245-257. 
Pimentel, T. C., A. G. Cruz, and S. H. Prudencio. 2013. Influence of long-chain inulin and Lactobacillus paracasei subspecies paracasei on the sensory profile and acceptance of a traditional yogurt. J. Dairy Sci. 96:6233-6241.

R Development Core Team. 2012. R: A language and environment for statistical computing. R Foundation for Statistical Computing, Vienna, Austria. http://www.r-project.org.

Saad, N., C. Delattre, M. Urdaci, J. M. Schmitter, and P. Bressollier. 2013. An overview of the last advances in probiotic and prebiotic field. Lebenson. Wiss. Technol. 50:1-16.

Santos, B. A., M. A. R. Pollonio, A. G. Cruz, V. C. Messias, R. A. Monteiro, T. L. C. Oliveira, J. A. F. Faria, M. Q. Freitas, and H. M. A. Bolini. 2012. Ultra-flash profile and projective mapping for describing sensory attributes of prebiotic mortadellas. Food Res. Int. $54: 1705-1711$.

SAS Institute. 2009. SAS User's Guide: Statistics. Version 9.1.2. SAS Institute Inc., Cary, NC.

Siró, I., E. Kápolna, B. Kápolna, and A. Lugasi. 2008. Functional food. Product development, marketing and consumer acceptance-A review. Appetite 51:456-467.
Souza, V. R., A. C. M. Pinheiro, J. D. S. Carneiro, S. M. Pinto, L. R. Abreu, and C. C. Menezes. 2011. Analysis of various sweeteners in petit Suisse cheese: Determination of the ideal and equivalent sweetness. J. Sens. Stud. 26:339-345.

Verbeken, D., K. Bael, O. Thas, and K. Dewetiinck. 2006. Interactions between $\kappa$-carrageenan, milk proteins and modified starch in sterilized dairy desserts. Int. Dairy J. 16:482-488.

Vickers, Z. 1988. Sensory specific satiety in lemonade using a just right scale for sweetness. J. Sens. Stud. 3:1-8.

Villegas, B., A. Tárrega, I. Carbonell, and E. Costell. 2010. Optimising acceptability of new prebiotic low-fat milk beverages. Food Qual. Prefer. 21:234-242.

Walkeling, I. N., and J. H. MacFie. 1995. Designing consumer trials balanced for first and higher orders of carry-over effect when only a subset of $k$ samples from $t$ may be tested. Food Qual. Prefer. 6:299-308.

Wiet, S. G., and P. K. Beyts. 1992. Sensory characteristics of sucralose and other intensity sweeteners. J. Food Sci. 57:1014-1019. 